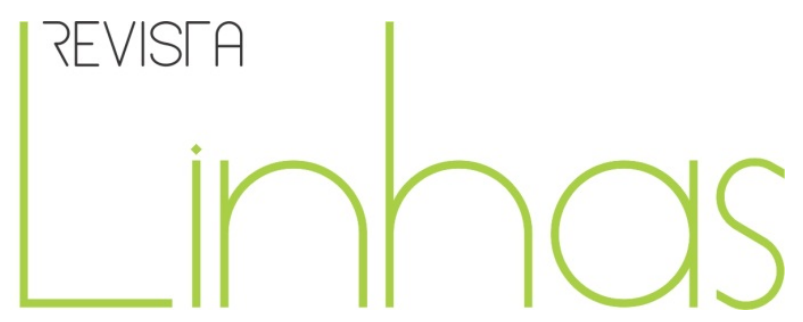

\title{
O uso do computador no processo de ensino e aprendizagem: questões de representação social ${ }^{1}$
}

\begin{abstract}
Resumo
Este trabalho apresenta os resultados de uma pesquisa que teve por objetivo geral identificar e analisar os pressupostos teóricometodológicos que norteiam a prática de professores dos anos iniciais no uso do computador no processo de ensino e aprendizagem. Como objetivo específico, busca identificar e analisar as representações sociais dos professores sobre 0 uso do computador no processo de ensino e aprendizagem. A pesquisa assumiu abordagem qualitativa com delineamento descritivoexplicativo e possuiu duas fases de coleta de dados: a) aplicação de questionário; b) acompanhamento da prática cotidiana dos professores de uma escola selecionada e entrevista semiestruturada. A análise dos dados se deu mediante análise de conteúdo. Por meio da inter-relação dos dados presentes no questionário, da observação e da entrevista, constatamos que os professores pesquisados apresentam um discurso que não coincide com a prática docente no uso do computador no processo educativo. $O$ aporte teórico expresso pelos professores participantes da pesquisa vai ao encontro de pressupostos construtivistas e/ou sociointeracionistas, mas a prática docente se afina, prioritariamente, a pressupostos comportamentalistas. Observamos questões de representação social quando os discursos dos professores participantes não correspondem às suas práticas. Associado a isso, ou como causa dessas condições, temos a insuficiência, a inadequação ou a ausência de formação docente para o uso do computador no processo educativo, que levam à subutilização desse recurso.
\end{abstract}

Palavras-chave: Práticas Pedagógicas. Computador. Representação Social.

\section{Para citar este artigo:}

SILVA, Analígia Miranda da; LIMA, Cláudia Maria. O uso do computador no processo de ensino e aprendizagem: questões de representação social. Revista Linhas, Florianópolis, v. 14, n. 27, jul./dez. 2013. p. $158-178$.

DOI: $10.5965 / 1984723814272013158$

http://dx.doi.org/10.5965/1984723814272013158

\footnotetext{
${ }^{1}$ Pesquisa financiada pela Capes.
}

\section{Analígia Miranda da Silva}

Doutoranda em Educação pela

Universidade Estadual Paulista UNESP.

analigiamiranda@gmail.com

\section{Cláudia Maria Lima}

Doutorado em Educação e professora da Universidade Estadual Paulista - UNESP. claudiamarialima@uol.com.br 


\title{
The use of computer in the process of teaching and learning: issues of social representation
}

\begin{abstract}
This paper presents the results of a study aimed at identifying and analyzing the theoretical and methodological principles that guide the practice of teachers in the early years of computer use in the teaching and learning. Specific objectives we seek to identify and analyze the social representations of teachers on the use of computers in teaching and learning. The research took a qualitative approach with a descriptive-explanatory and owned two phases of data collection: a) a questionnaire b) monitoring the daily practice of teachers in a selected school and semi-structured interview. The analysis of data was done through content analysis. Through the interrelationship of the data in the questionnaire, observation and interview, we found that the teachers surveyed have an address that does not match the teaching practice in the use of computers in the educational process. The theoretical expressed by teachers participating in the research meets constructivist beliefs and / or sociointeractionists but teaching practice thins primarily to behavioral assumptions. Observe social issues of representation when the speeches of the participating teachers did not correspond to their practices. Associated with this or as a cause of these conditions have failure, inadequacy or absence of teacher training for the use of computers in the educational process leading to under-utilization of this resource.
\end{abstract}

Keywords: Pedagogical Practices. Computer. Social Representation. 


\section{Introdução}

A educação contemporânea demanda reflexão sobre as novas finalidades que se desvelam e se constituem em desafios às práticas pedagógicas. A introdução das tecnologias digitais de informação e comunicação parece ser uma dessas novas demandas, pois provocam mudanças na sociedade, nas relações dos sujeitos com o saber, bem como o surgimento de novas necessidades de formação (KENSKI, 2003).

Estas mudanças, que de fato estão ocorrendo na sociedade contemporânea, exigiriam, de forma óbvia, adaptações nos processos educativos e, consequentemente, no trabalho pedagógico do professor que deveria ser (re)pensado para atender a estas novas demandas. No entanto, essas necessárias adaptações podem esbarrar em representações que impedem as transformações almejadas. Sobre isso, Badia e Monereo (2010) observam que, de forma geral, quando tecnologias são inseridas na escola, não há mudanças significativas nas práticas pedagógicas, por causa de “[...] um sistema educacional majoritariamente ancorado em uma epistemologia objetivista e experimentalista, em um pensamento lógico-formal, em uma didática transmissiva [...]" (BADIA \& MONEREO, 2010, p. 311).

Sendo assim, partimos do pressuposto de que questões de representação social (MOSCOVICI, 2003) podem determinar a forma como os professores fazem uso das tecnologias no processo de ensino e aprendizagem. Assim, conhecendo as representações sociais docentes sobre o uso do computador na educação, podemos fazer inferências de suas práticas e, talvez, propor algumas interferências.

Propondo-nos compreender o uso pedagógico das tecnologias na educação escolar, este estudo tem por objetivo geral a identificação e análise dos pressupostos teórico-metodológicos que norteiam a prática de professores dos anos iniciais do ensino fundamental no uso do computador no processo de ensino e aprendizagem. Como objetivo específico, busca identificar e analisar as representações sociais (MOSCOVICl, 2003) dos professores sobre o uso do computador no processo de ensino e aprendizagem. 


\section{A prática docente e as tecnologias digitais de informação e comunicação na educação: questões de representação social}

A evolução histórica das tecnologias, desde os primeiros artefatos utilizados pelo homem para dominar a natureza, transformá-la e adaptar-se a ela, até os dias atuais, em que dispõe de recursos tecnológicos sendo criados e tornando-se obsoletos com velocidade ímpar, influi sobre o pensar humano. Como explicita Leontiev (1978, p. 265) "os progressos realizados na produção de bens materiais são acompanhados pelo desenvolvimento da cultura dos homens; o seu conhecimento do mundo circundante e deles mesmos enriquece-se [...]". No cenário atual, destacam-se como bens materiais, as tecnologias digitais de informação e comunicação que, segundo Coll e Monereo (2010, p. 17):

Entre todas as tecnologias criadas pelos seres humanos, aquelas relacionadas com a capacidade de representar e transmitir informação ou seja, as tecnologias da informação e da comunicação - revestem-se de uma especial importância, porque afetam praticamente todos os âmbitos de atividades das pessoas, desde as formas e práticas de organização social até o modo de compreender o mundo, de organizar essa compreensão e de transmitíla para outras pessoas. As TIC têm sido sempre, em suas diferentes fases de desenvolvimento, instrumentos para pensar, aprender, conhecer, representar e transmitir para outras pessoas e para outras gerações os conhecimentos adquiridos.

Temos que a atual conjuntura é caracterizada pela sociedade da informação, globalizada e organizada em torno de processos próprios de acesso a informações e sua seleção (DEMO, 2000 e ASSMANN, 2000). Neste contexto, as tecnologias de informação e comunicação ocupam um lugar importante, pois "caracterizadas como midiáticas, são, portanto, mais do que simples suportes. Elas interferem em nosso modo de pensar, sentir, agir, de nos relacionarmos socialmente e adquirirmos conhecimentos" (KENSKI, 2003, p. 23-24). Portanto, para analisar o cenário atual e qual o lugar das tecnologias nesse contexto, devemos ir além da análise de termos técnicos. É necessário compreender as relações que o homem estabelece com essas ferramentas. 
Levy (1999, p. 22), em sua obra Cibercultura, aborda a questão do humano e as tecnologias, expondo que é impossível separar o homem de suas relações com os aparatos tecnológicos. Para o autor:

É impossível separar o humano de seu ambiente material, assim como dos signos e das imagens por meio dos quais ele atribui sentido à vida e ao mundo. Da mesma forma não podemos separar o mundo - e menos ainda sua parte artificial - das idéias por meio das quais os objetos técnicos são concebidos e utilizados, nem dos humanos que os inventam, produzem e utilizam.

Neste sentido, não há como isolarmos a escola dos avanços tecnológicos que transformam a sociedade atual. As tecnologias adentram o campo escolar por meio de políticas públicas ou pelos usos informais que alunos e professores fazem destes recursos. Entretanto, o aproveitamento dessa nova situação em processos pedagógicos que contemplem o aprender dos alunos depende da (re)construção de práticas, currículos, metodologias que podem não corresponder aos paradigmas seguidos na educação atual. Para Gomes (2002, p. 120) "somente a utilização dos recursos das tecnologias de informação e comunicação pela escola não garante mudanças na qualidade da educação. É necessário repensar os paradigmas existentes para a adoção de novas práticas educativas."

Aliado ao resultado de mudanças nas formas de se relacionar, comunicar e conhecer, propiciadas pelo avanço dos recursos tecnológicos, com o redimensionando de aspectos socioculturais, políticos e institucionais, nos deparamos com a iminência da revisão de currículos e práticas educacionais, decorrente do surgimento de novas necessidades formativas. As potencialidades educacionais das tecnologias digitais só são evidenciadas mediante práticas pedagógicas estruturadas e organizadas que contemplem o aluno que, fora da instituição escolar, está adaptado a novas dimensões e diferentes ritmos relacionados ao processo do aprender, não condizentes com a atual realidade das escolas brasileiras. Acerca disso, Moreira e Kramer (2007, p. 1.048) apontam para o fato inegável de que há mudanças significativas acontecendo e que há "[...] novos aparatos tecnológicos que formam e informam uma geração", culminando em uma nova cultura da aprendizagem. 
Compreender aspectos sociais, culturais e educativos é condição primeira para a análise sobre como as tecnologias invadem o contexto atual e como permeiam aspectos relacionados à formação humana. É fundante olhar a escola enquanto instituição inserida nesta sociedade tecnológica em que a compreensão das “[...] mudanças que remodelam a sociedade na contemporaneidade perpassa, necessariamente, por uma análise da dinâmica do mundo em constante transformação" (NEVES, 2011, p. 105).

Assim, cabe um questionamento sobre como as tecnologias digitais de informação e comunicação estão inseridas na escola, como esta se apropria dos novos recursos e o quanto eles podem contribuir enquanto avanços que possam resultar em melhoria dos indicadores educacionais do País. Isso, necessariamente, implica avaliar se os professores estão preparados para o uso das tecnologias em sua prática pedagógica, considerando como o seu aluno aprende com tais recursos.

Entramos, neste momento, no campo das representações sociais. Mas o que significa falar em representações? O que entendemos por representação? Chegamos a vêla como elemento capaz de influenciar ou não transformações no campo educacional? Ao falar sobre representações, buscamos fundamentos na teoria das representações sociais (MOSCOVICI, 2003), pois ela nos permite um amplo campo de análise para compreendermos o que pensa o professor acerca do uso das tecnologias digitais de informação e comunicação na educação escolar e em que fundamenta as suas práticas pedagógicas com o uso destes recursos.

Temos que o ser humano é impregnado por ideias e significações socialmente construídas durante toda sua existência. Tais ideias e significações nascem de construções e leituras da realidade social que o sujeito vivencia no meio a que pertence. Dessa maneira, a teoria das representações sociais nos permite compreender como se opera o processo de construção de um dado objeto a partir de sua percepção. Segundo Jodelet (2001, p. 22), representação social: 
É uma forma de conhecimento, socialmente elaborada e partilhada, com um objetivo prático, e que contribui para a construção de uma realidade comum a um conjunto social. Igualmente designada saber do senso comum ou ainda saber ingênuo, natural essa forma de conhecimento é diferenciada, entre outras, do conhecimento científico. Entretanto, é tida como um objeto de estudo tão legítimo quanto este devido à sua importância na vida social e à elucidação possibilitadora dos processos cognitivos e das interações sociais.

O pressuposto da abordagem da representação social é de o homem possuir uma necessidade essencial de compreender a realidade social na qual está inserido e dar-lhe significado, ou seja, a representação social é uma construção do indivíduo enquanto sujeito social.

Na perspectiva da Psicologia Social, o homem é concebido como um ser social que se constitui mediante processos interacionais entre ele e a sociedade. Uma vez que a representação social se constitui como produto e processo de uma elaboração psicológica e social do real, ou seja, designa uma forma de pensamento social (JODELET, 2001), temos que a teoria das representações sociais se situa no campo dos estudos psicossociais e nos fornece fundamentação para o estudo sobre o pensamento e as condutas de pessoas e grupos sociais. Para Albuquerque (2005, p. 20) tal teoria:

[...] possibilita ao pesquisador apreender os elementos constituintes da prática social, superar o caráter puramente analítico de seu trabalho e identificar a gênese das condutas e das comunicações humanas. Em conseqüência de sua natureza interpretativa, possibilita a observação dos mais variados componentes da realidade individual e coletiva, na qual estão expressos explícita ou implicitamente os resultados da ação do homem em sociedade.

Situando historicamente a teoria das representações sociais, temos que esta surgiu a partir dos estudos de Serge Moscovici sobre o conceito de representação coletiva de Durkheim (1968) ${ }^{2}$. A tal respeito, Moscovici (2001, p. 47) afirma que "o verdadeiro inventor do conceito é Durkheim, na medida em que fixa os contornos e lhe reconhece o direito de explicar os fenômenos mais variados na sociedade". Contudo, ao

\footnotetext{
${ }^{2}$ Moscovici (2001, p. 47) aponta que "em Durkheim, a representação designa, prioritariamente, uma ampla classe de formas mentais (ciências, religiões, mitos, espaço, tempo), de opiniões e saberes sem distinção. A noção é equivalente à de idéia ou à de sistema, não estando suas características cognitivas especificadas".
} 
contrário de Durkheim que associa representações coletivas às representações homogêneas e compartilhadas pela sociedade, para Moscovici (2001) as representações sociais são dinâmicas e heterogêneas, ocorrendo uma intersecção entre o social e o individual.

A opinião deste autor (MOSCOVICl, 2003, p. 58) é que as representações sociais nascem e se desenvolvem na tensão entre a subjetividade do sujeito e a necessidade de tornar familiar o que lhe parece estranho. Generalizando: cria-se, então, um significado sobre a realidade social e, a partir daí, convencionam-se os objetos de modo que possam ser classificados. Para o autor:

Quando tudo é dito e feito, as representações que nós fabricamos duma teoria científica, de uma nação, de um objeto, etc - são sempre o resultado de um esforço constante de tornar comum e real algo que é incomum (não-familiar), ou que nos dá um sentimento de nãofamiliaridade.

Desse modo, as representações sociais constituem um sistema de ideias, valores e práticas que têm por função possibilitar ao sujeito que se oriente em seu meio social e material e o controle, e permitir-lhe que a comunicação seja possível na comunidade à qual o sujeito pertence. Isso se dá por meio da nomeação e classificação das variáveis e dos aspectos do seu mundo e de sua história pessoal e social.

Temos também que as representações sociais envolvem um tipo específico de conhecimento, o qual fornece embasamento na elaboração de comportamentos e comunicação entre os indivíduos no espaço da vida cotidiana. De acordo com Cavalcanti (2004, p. 38):

A comunicação, movimento das expressões dos sujeitos, possibilita ao homem uma forma de estabelecer relações e práticas sociais ao mesmo tempo em que orienta a ação humana e as relações que são estabelecidas, promovendo a construção do conhecimento e da realidade social.

Em relação aos processos que geram representações sociais, Moscovici (2003) explicita que representações são geradas a partir de dois mecanismos cognitivos denominados ancoragem e objetivação. A ancoragem permite que o significado de 
determinado fato seja comparado em relação a algumas categorias e imagens já assentadas em nosso universo simbólico, ou seja, permite que o fato seja classificado e nomeado pelo indivíduo. Dessa forma, o processo de ancorar nos fornece bases para que julguemos determinados fatos e pessoas a partir de nossas crenças. Já a objetivação consiste em estabelecer uma relação entre o conceito e a imagem para que a ideia possa ser determinada, ou seja, a representação assume forma concreta uma vez que, unindo “a idéia de não-familiaridade com a de realidade, torna-se a verdadeira essência da realidade" (MOSCOVICl, 2003, p. 71).

Por meio da linguagem, verbal ou não, significados são repassados num processo de comunicação socializada e, a partir daí, normas, regras e concepções da sociedade vão sendo internalizadas pelo sujeito. Portanto, considerar em uma pesquisa questões de representação social nos permitirá captar o complexo movimento de informações, valores, modelos, símbolos, desejos, normas e demandas que, articuladas, circunscrevem o sentido do objeto para os sujeitos da pesquisa e determinam suas condutas e comunicações.

Neste sentido, as representações sociais dos professores sobre o uso do computador no processo de ensino e aprendizagem podem determinar a forma como eles fazem uso dessa ferramenta nos processos educativos e como a compreendem em suas possibilidades formativas.

\section{Percurso metodológico}

O presente artigo apresenta e discute os resultados de uma pesquisa cujo objetivo geral consistiu em identificar e analisar os pressupostos teórico-metodológicos que norteiam a prática de professores dos anos iniciais no uso do computador no processo de ensino e aprendizagem. Para responder ao objetivo geral delineamos o seguinte objetivo específico: identificar e analisar as representações sociais dos professores sobre o uso do computador no processo de ensino e aprendizagem. 
Para tanto, a pesquisa assumiu a abordagem qualitativa (LÜDKE \& ANDRÉ, 1986) de delineamento descritivo-explicativo (GIL, 2008), com duas fases de coleta de dados.

A primeira fase deste estudo teve como instrumento de pesquisa o questionário de perguntas abertas e fechadas. Como informantes da pesquisa, tivemos 42 professores que atuam do primeiro ao quinto ano do ensino fundamental de seis escolas da rede municipal de um município do interior de São Paulo, de porte médio, com aproximadamente 400 mil habitantes, e uma rede de ensino com 88 escolas municipais que atendem da educação infantil ao nono ano do ensino fundamental.

As escolas participantes da pesquisa estavam inseridas em um projeto de inclusão digital $^{3}$, vinculado à Secretaria Municipal de Educação. Tal projeto se caracteriza como uma rede de comunicação digital que interliga as escolas do município e possui um sistema de administração escolar e conjunto de módulos (softwares educativos) utilizados em laboratórios de informática implantados nas escolas do município.

Para a análise dos dados obtidos por meio dos questionários, selecionamos como técnica de apreciação dos dados a Análise de Conteúdo (BARDIN, 1977); o ponto de partida deste procedimento é a mensagem. Além de ser um conjunto de técnicas de análise das comunicações, a finalidade da Análise de Conteúdo é a produção de inferências. Produzir inferências faz com que a Análise de Conteúdo não seja um procedimento puramente descritivo, mas um procedimento que relaciona um dado com alguma teoria.

A segunda fase da pesquisa foi composta por observação e entrevista. Como informantes da pesquisa, temos cinco professores que atuam do primeiro ao quinto ano do ensino fundamental de uma escola dentre as seis inicialmente pesquisadas.

A observação ocorreu de forma semiestruturada. A técnica consiste em focar no objetivo central da pesquisa, mas sem desconsiderar outros aspectos que possam contribuir para uma melhor aproximação da realidade observada (VIANNA, 2007). Sobre a característica da entrevista, podemos denominá-la como semidirigida (SZYMANSKI, 2004), sendo afinada com os objetivos da pesquisa.

\footnotetext{
${ }^{3}$ Por questões éticas, não incluímos o nome do referido projeto neste trabalho.
} 
Para a análise dos dados da observação, optamos por organizá-los e tabulá-los de acordo com uma matriz de observação, identificando ocorrências que vão ao encontro dos objetivos da pesquisa, sendo geradas categorias relevantes. Para análise dos dados da entrevista, valemo-nos da técnica de Bardin (1977), recurso também utilizado na primeira fase da pesquisa.

Ao final, realizamos uma triangulação na coleta e análise dos dados com vistas a melhor nos aproximar dos objetivos do estudo.

\section{Resultados e discussão}

Para iniciar a discussão dos dados, precisamos explicitar que os indicadores delineados foram determinados pelo objetivo do estudo, que, por sua vez, norteou o instrumento de pesquisa. Para responder ao objetivo geral de identificar e analisar os pressupostos teórico-metodológicos que norteiam a prática de professores dos anos iniciais do ensino fundamental no uso do computador no processo de ensino e aprendizagem, estabelecemos, como objetivo específico, a necessidade de identificamos e analisar as representações sociais dos professores sobre o uso do computador no processo de ensino e aprendizagem. Para tanto, procuramos identificar por meio dos instrumentos de pesquisa:

- $\quad$ As representações sociais dos professores sobre ensino;

- $\quad$ As representações sociais dos professores sobre aprendizagem;

- $\quad$ As representações sociais sobre ensino mediado pelo computador;

- $\quad$ As representações sociais sobre aprendizagem mediada por computador.

Iniciamos a discussão dos dados partindo da primeira fase do estudo realizada por meio de questionário. Posteriormente, traremos a análise dos dados da observação e entrevista, já que entendemos ser necessária uma triangulação na coleta e análise dos dados, constituída por questionário, observação e entrevista, com o objetivo de melhor 
aproximação da complexidade da prática docente no uso do computador no processo educativo.

Os dados obtidos por meio do questionário indicam que os professores participantes da pesquisa têm feito uso do computador tanto no seu dia-a-dia quanto em sala de aula para fins de ensino e aprendizagem. Apesar de o uso do computador na escola estar atrelado a um projeto da prefeitura do município, os professores participantes expressam, na sua totalidade, que concordam com inserção das tecnologias na escola.

Contudo, percebemos um uso pedagógico mais voltado a questões de ensino do que a questões de aprendizagem. As expressões docentes indicam o computador como ferramenta para o ensino em detrimento de uma ferramenta para aprendizagem ou de expressão do pensamento. Neste sentido, temos representações sociais sobre ensino e aprendizagem aproximando-se de práticas tradicionais. Corroborando essa constatação, Chaib (2002, p. 60) escreve:

Ensinar é considerado tradicionalmente como uma profissão bastante conservadora. Apesar de todas as teorias científicas em Educação, a maioria dos professores percebe o ensino como uma prática social e uma arte, em lugar de uma ciência. [...] Considerando estes fatos, é fácil entender por que mudanças impostas freqüentemente a professores, geram conflitos entre valores velhos e novos de ensinar. Em nossa tentativa para generalizar a aplicação de tecnologia moderna em Educação, raramente levamos em conta a dificuldade que as pessoas têm em aceitar novos argumentos comparados as suas representações prévias.

Além disso, identificamos representações sociais docentes sobre o uso do computador enquanto elemento exclusivamente motivador, distanciando-se do processo de construção de saberes por seus alunos. Pressupomos que a escolha da utilização do computador no processo educativo deva ir além de seu caráter motivacional, demandando reflexão por parte do professor acerca de como o seu aluno aprende com o uso de tal recurso, visando à estruturação de sua aula de acordo com os objetivos pedagógicos que almeja. Para Belloni \& Gomes (2008, p. 742), “o desafio da escola é o de potencializar as virtudes técnicas das TIC, colocando-as a serviço de aprendizagens significativas e não convencionais, mais adequadas às culturas jovens e infantis.”. 
Questionados sobre mudanças possíveis na prática pedagógica quando o computador é utilizado no processo educativo, os professores participantes focam mais a questão da aprendizagem. Apesar de anteriormente a presença do computador no processo educativo estar mais relacionado ao ensinar, quando questionados sobre mudanças de práticas com o uso desse instrumento a aprendizagem é colocada em evidência. Tal fato indica uma percepção de parte do professor, ainda que primária, de que sua inserção necessariamente implica nova postura, voltada ao aluno e, consequentemente, à aprendizagem. Esta percepção docente é importante, pois, como afirmam Mamede-Neves \& Duarte (2008, p. 785):

A escola terá melhores condições de cumprir seu papel de escolarizar as novas gerações de nativos digitais se conseguirmos levar em conta, na organização do currículo, nas práticas escolares e na escolha de nossos métodos, formas de aprender que não se enquadram em nossos paradigmas.

Sobre os pressupostos teórico-metodológicos que norteiam a prática docente no uso do computador em processos de ensino e aprendizagem observamos ocorrências que se enveredam tanto para o comportamentalismo quanto para o construtivismo, sendo que argumentos afinados aos moldes comportamentalistas são mais presentes. Argumentos como reforço da aprendizagem, assimilação e construção do conhecimento permearam os discursos docentes e, em várias ocorrências, em uma mesma fala. Depreendemos que questões de representação social permeiam os argumentos dos professores participantes sobre o aprender com o uso do computador, em razão das diferentes abordagens de aprendizagem em um mesmo discurso.

A análise dos dados obtidos por meio do questionário, além de nos aproximar das representações docentes acerca de pressupostos teórico-metodológicos que norteiam a prática pedagógica no uso do computador também nos aproximou das políticas de inserção das tecnologias na educação escolar. No caso específico desse estudo, a inserção do computador nas escolas participantes da pesquisa não foi acompanhada de uma formação estruturada e sólida dos professores, sendo desconsiderada a literatura acerca da informática educativa que atribui especial importância à questão da formação 
docente, bem como sobre o aprender com o uso do computador (PORTO, 2006; GARCIA, 2005; ZAVASKI, 2005).

O resultado da insuficiência, inadequação ou ausência de formação docente é demonstrado nos discursos dos professores, uma vez que não obtivemos explicação científica coerente por parte deles sobre como as teorias da aprendizagem subsidiam suas práticas pedagógicas no uso do computador no processo de ensino e aprendizagem; além disso, questões de representação social ficam evidentes. Para Alonso (2008, p. 756), o problema da incorporação das tecnologias de informação e comunicação na educação escolar reside no fato de que é transferido “[...] para as 'mãos' dos envolvidos diretamente com as práticas escolares/pedagógicas a empreitada da transformação, cabendo-lhes recriar fazeres e saberes de lógicas estranhas e alheias ao seu cotidiano."

Para embasar os dados obtidos por meio do questionário, recorremos à observação com o objetivo de confrontar o discurso docente com sua prática cotidiana.

Por meio da observação pudemos conhecer a prática cotidiana dos professores no uso do computador no processo de ensino e aprendizagem e depreender os saberes mobilizados enquanto este recurso é utilizado, bem como relacionar o discurso à sua prática cotidiana.

Constatamos que o laboratório de informática das escolas participantes dessa fase do estudo tem sido subutilizado, uma vez que a ocorrência mais significativa em frequência é o uso de jogos exclusivamente para fins de entretenimento. Em segundo lugar em frequência, registramos o uso dos softwares educativos do projeto de informática educativa do município, os quais, em uma análise realizada sobre eles, nos indicaram que se aproximam da vertente comportamentalista, que se utiliza de reforçadores e o ensino compreende a ação de pequenos passos com propósitos préestabelecidos.

Com a observação realizada, depreendemos que o pressuposto teóricometodológico mais utilizado pelos professores participantes da pesquisa no uso do computador no processo educativo é o comportamentalismo. A utilização de tal pressuposto não resulta, no entanto, de uma escolha docente, mas de uma ausência e/ou 
insuficiência de formação que impede ao professor selecionar recursos apropriados e organizar atividades pedagógicas com o uso do computador de acordo segundo abordagens de aprendizagem a seu julgamento mais adequadas à sua intencionalidade pedagógica, uma vez que a sua prática é restrita ao uso de:

[...] softwares educativos concebidos para potenciar a aprendizagem e o trabalho do professor, mas que possuem metodologias fechadas, não permitindo a participação direta do professor e dos alunos. Softwares que contêm aulas prontas (pacotes), sem possibilidade de personalização, de modificação de seus conteúdos, porque são estáticos, fixos, com links arborescentes, limitado (SILVA, 2010, p. 235, grifo do autor).

Voltando aos dados obtidos por meio do questionário, temos que os professores participantes expressam que o construtivismo e/ou o sociointeracionismo são as abordagens utilizadas em suas práticas; no entanto, não obtivemos explicação consistente, por parte desses mesmos professores, de como estas teorias subsidiam processos de ensino e aprendizagem com o uso do computador. Acreditamos que os professores participantes não explicam consistentemente como tais teorias orientam suas práticas no uso do computador, por não as utilizarem efetivamente, uma vez que seguem a orientação teórico-metodológica dos módulos pré-estabelecidos e de vertente comportamentalista. Os dados indicam que os professores participantes não possuem formação ou, quando a possuem, esta não é adequada e/ou suficiente para o uso do computador no processo educativo com outros recursos, que não módulos préestabelecidos, propiciadores de uma prática pedagógica em consonância com os pressupostos teórico-metodológicos expressos por eles.

No terceiro momento da pesquisa, para compreender tais práticas no uso do laboratório de informática, entrevistamos os professores participantes da etapa da observação.

Por meio das entrevistas reforçamos a constatação de que o pressuposto comportamentalista, que permeia suas práticas, se deve ao caráter dos softwares educativos utilizados nos laboratórios de informática, programados com esta orientação teórico-metodológica. Assim, apesar de os professores acreditarem que o uso do 
computador no processo educativo tivesse que se apoiar em pressupostos construtivistas e/ou sociointeracionistas, não os utilizam em suas práticas cotidianas. Associada a isso, ou como causa dessas condições, temos a ausência, a insuficiência ou a inadequação de formação docente para o uso do computador no processo educativo, o que leva à subutilização do recurso (OLIVEIRA; HAGUENAUER; CORDEIRO, 2006).

Tal constatação demanda atenção tendo em vista a importância da formação docente, pois, para que o professor atue no processo de ensino e aprendizagem com o uso das tecnologias, é necessário que ele tenha competência para administrar tais recursos mediante abordagens de ensino e aprendizagem que compreendam como o aluno aprende (MAMEDE-NEVES \& DUARTE, 2008).

Superar o uso das tecnologias sob uma abordagem instrumental e olhar para elas como ferramentas estruturantes de novas práticas pedagógicas abertas, flexíveis e que podem propiciar construção de saberes, corresponde a considerar os alunos como sujeitos do seu processo de conhecer e possuidores de uma nova ecologia cognitiva (ASSMANN, 2000).

\section{Considerações finais}

No atual cenário, no qual os alunos representam e significam o mundo de forma diferenciada, é necessário um novo perfil de professor, que detenha competências adequadas às necessidades formativas atuais. Para Lalueza, Crespo \& Camps (2010, p. 60), "o impacto cognitivo das tecnologias reside nas práticas dentro das quais elas são utilizadas, no seu papel de mediação das atividades realizadas por meio dessas práticas". A iminência de novos espaços de conhecimento, propiciados pelas diversas tecnologias de informar e comunicar, impõe desafios à educação escolar e, em especial, à formação docente. É preciso que professor compreenda que o seu aluno participa deste novo contexto sociocultural e se integra à complexidade do mundo contemporâneo, demandando reconfiguração de práticas pedagógicas. 
De acordo com Coll \& Monereo (2010, p. 34), para analisar como se dão as mudanças nas práticas educacionais com o uso das tecnologias é necessário:

[...] um olhar sobre a natureza das mudanças que podem ocorrer nos atores educacionais, especialmente alunos e professores, e em suas formas de interação. Mais concretamente, trata-se de analisar o que muda (os discursos, as representações, as práticas, os processos, os resultados, etc). E, também, saber como acontecem essas mudanças e se elas têm características diferentes daquelas que ocorrem em situações e atividades educacionais nas quais as TIC não estão presentes.

Dessa forma, é necessário que o professor tenha clareza acerca de quais pressupostos teórico-metodológicos precisam ser mobilizados na orientação de sua prática com o uso das tecnologias, contemplando suas intencionalidades pedagógicas.

Na pesquisa aqui relatada, precisamos observar que a inserção do computador nas escolas que participaram da investigação não foi acompanhada de formação docente adequada e estruturada para o uso desse recurso. Os dados revelaram necessidades, ausência ou insuficiência de formação docente. Em decorrência, os professores acabam por utilizar o computador de acordo com suas representações sociais sobre ensino e aprendizagem mediados por esse recurso. Apesar de os professores participantes se manifestarem como construtivistas e/ou sociointeracionistas, não havia embasamento em suas falas e/ou práticas que confirmasse tais pressupostos.

Como exemplo, questionados sobre a (as) teoria (s) da aprendizagem que direciona $(\mathrm{m})$ suas ações quando usam o computador no processo de ensino e aprendizagem, os professores traziam argumentos que se relacionavam a pressupostos sociointeracionistas e construtivistas. No entanto, quando questionados sobre a sua prática surgia, em maior frequência nas falas docentes, a abordagem comportamentalista

Percebemos também que os professores participantes utilizam o laboratório de informática, o mais das vezes, como momento de lazer ou seguindo a orientação teóricometodológica de módulos educativos pré-estabelecidos, que, por sua vez, são de características comportamentalistas. Assim, apesar de acreditarem que o uso do computador no processo educativo tenha que se apoiar em pressupostos construtivistas e/ou sociointeracionistas não utilizam tais abordagens em suas práticas cotidianas. 
Os dados desse estudo indicam a necessidade de processos formativos que garantam competência ao professor no uso do computador no processo de ensino e aprendizagem, dispensando softwares educativos pré-estabelecidos e com características de programas fechados, pouco indicados para a construção de conceitos pelos alunos, função básica da educação (GOMES, 2008).

Inserir computadores na escola não é o único passo a ser dado para um processo educativo que se diga inovador. Alonso (2008, p. 763) corrobora esta afirmação quando observa que "[...] reconhecemos, pouco a pouco, que a introdução de novos artefatos técnicos nas escolas não redunda em melhoria efetiva do processo ensino/aprendizagem.”. A formação docente é primordial para que a inserção dos computadores na escola não resulte apenas em um uso improdutivo de recursos financeiros e não resultem em melhoria dos indicadores educacionais do País.

É necessário que novos saberes sejam incorporados à prática docente, o que demanda uma formação condizente com este novo momento que atravessa a educação escolar. Cabe oferecer bases formativas para que o professor compreenda o computador em suas potencialidades e limitações no processo de ensino e aprendizagem.

\section{Referências}

ALBUQUERQUE, Lia Matos Brito de. Habitus, representações sociais e a construção identitária dos professores de Maracanaú. 2005. 152 f. Dissertação (Mestrado em Educação) - Universidade Federal do Rio Grande do Norte, Natal, 2005.

ALONSO, Kátia Morosov. Tecnologias da informação e comunicação e formação de professores: sobre rede e escolas. Educ. Soc., Campinas, v. 29, n. 104, out. 2008. p. 748768.

ASSMANN, Hugo. A metamorfose do aprender na sociedade da informação. Ci. Inf., Brasília v. 29, n. 2, mai./ago. 2000. p. 7-15, Disponível em: <http://www.scielo.br/pdf/ci/v29n2/ao2v29n2.pdf >. Acesso em: 11 fev. 13.

BADIA, Antoni; MONEREO, Carles. Ensino e aprendizado de estratégias de aprendizagem em ambientes virtuais. In: COLL, César; MONEREO, Carles. (Orgs.). Psicologia da educação 
virtual: aprender e ensinar com as tecnologias da informação e da comunicação. Porto Alegre: Artmed, 2010. p. 311-328.

BARDIN, Laurence. Análise de conteúdo. Lisboa: Edições 70, 1977.

BELLONI, Maria Luiza; GOMES, Nilza Godoy. Infância, mídias e aprendizagem: autodidaxia e colaboração. Educ. Soc., Campinas, v. 29, n. 104 - Especial, out. 2008. p. 717-746.

CAVALCANTI, Luciana Cordeiro. Ensino, aprendizagem e informática na educação: um estudo das representações sociais dos professores da educação básica. 2004. 138 f. Dissertação (Mestrado em Educação) - Universidade Federal de Pernambuco, Recife.

CHAIB, Mohamed. Frankstein na sala de aula: as representações sociais docentes sobre informática. Nuances, $n^{\circ}$. 8, set. 2002, p. 47-64.

COLL, César; MONEREO, Carles. Educação e aprendizagem no século XXI: novas ferramentas, novos cenários, novas finalidades. In: COLL, César; MONEREO, Carles. (Orgs.). Psicologia da educação virtual: aprender e ensinar com as tecnologias da informação e da comunicação. Porto Alegre: Artmed, 2010. p. 15-46.

DEMO, Pedro. Ambivalências da sociedade da informação. Ci. Inf., Brasília, v. 29, n. 2, mai./ago. 2000. p. 37-42. Disponível em:

<http://www.scielo.br/pdf/\%oD/ci/v29n2/a05v29n2.pdf>. Acesso em: 11 fev. 13.

GARCIA, Fernando. Formação de professores e o uso significativo de computadores na prática pedagógica. 2005. Dissertação (Mestrado em Educação) - Pontifícia Universidade Católica de São Paulo - São Paulo.

GIL, Antônio Carlos. Como elaborar projetos de pesquisa. $3^{\text {a }}$. ed. São Paulo, Atlas, 2008.

GOMES, Alex Sandro. Referencial teórico construtivista para avaliação de software educativo. Revista Brasileira de Informática na Educação, v. 16, n. 2, mai./ago, 2008. p. 9-21. Disponível em: <http://ceie-sbc.educacao.ws/pub/index.php/rbie/article/viewFile/75/73>. Acesso em: 7 abr. 13.

GOMES, Nilza Godoy. Computador na escola: novas tecnologias e inovações educacionais. In: BELLONI, Maria Luiza. (Org.). A formação na sociedade do espetáculo. São Paulo: Loyola, 2002. p. 119-134.

JODELET, Denise. Representações sociais: um domínio em expansão. In: JODELET, Denise (Org.). As representações sociais. Rio de Janeiro: Ed. UERJ, 2001. p. 17-44.

KENSKI, Vani Moreira. Tecnologias de ensino presencial e a distância. Campinas, SP: Papirus, 2003. 
LALUEZA, José Luis; CRESPO, Isabel; CAMPS, Silvia. As tecnologias da informação e da comunicação e os processos de desenvolvimento e socialização. In: COLL, César; MONEREO, Carles. (Orgs.). Psicologia da educação virtual: aprender e ensinar com as tecnologias da informação e da comunicação. Porto Alegre: Artmed, 2010. p. 47-65.

LEONTIEV, Alexis. O Homem e a cultura. In: LEONTIEV, Alexis. O desenvolvimento do psiquismo. Lisboa: Horizonte Universitário, 1978. p. 259-284.

LÉVY, Pierre. Cibercultura. São Paulo: Ed. 34, 1999.

LÜDKE, Menga; ANDRÉ, Marli Elisa Dalmazo Afonso de. Pesquisa em educação: abordagens qualitativas. SP: EPU, 1986.

MAMEDE-NEVES, Maria Apparecida Campos; DUARTE, Rosália. O contexto dos novos recursos tecnológicos de informação e comunicação e a escola. Educ. Soc., Campinas, v. 29, n. 104, out. 2008. Disponível em <http://www.scielo.br/pdf/es/v29n104/a0729104.pdf>. Acesso em: 19 abr. 2013.

MOREIRA, Antônio Flávio Barbosa; KRAMER, Sônia. Contemporaneidade, educação e tecnologia. Educ. Soc., Campinas, v. 28, n. 100, out. 2007.

MOSCOVICl, Serge. Das representações coletivas às representações sociais: elementos para uma história. In: JODETET. Denise (Org.). As representações sociais. Rio de Janeiro: Ed. UERJ, 2001. p. 45-66.

MOSCOVICl, Serge. Representações sociais: investigações em psicologia social. Petrópolis: Vozes, 2003.

NEVES, Bárbara Coelho. Pensata sobre a globalização e a necessidade de abordagem cognitiva para inclusão digital. Inf. cult. soc., Ciudad Autónoma de Buenos Aires, n. 24, jun. 2011. Disponível em: < http://www.scielo.org.ar/pdf/ics/n24/n24a06.pdf >. Acesso em: 25 mar. 2013.

OLIVEIRA, Altemar Sales de; HAGUENAUER, Cristina; CORDEIRO, Francisco. Uso de ambientes informatizados na prática do professor de informática do ensino superior privado. Revista Colabora-CVA, v. 3, n. 12, out. 2006. p. 1-13, Disponível em: <http://pead.ucpel.tche.br/revistas/index.php/colabora/article/viewFile/82/71>. Acesso em: 7 abr. 2013.

PORTO, Tânia Maria Esperon. As tecnologias de comunicação e informação na escola: relações possíveis... relações construídas. Rev. Bras. Educ., Rio de Janeiro, v. 11, n. 31, Abr. 2006. Disponível em: <http://www.scielo.br/scielo.php?script=sci_arttext\&pid=S141324782006000100005\&lng=en\&nrm=iso >. Acesso em: 15 abr. 13. 
SILVA. Marco. Docência interativa presencial e online. In: VALENTINI, Carla Beatriz; SOARES, Eliana Maria do Sacramento (Orgs.). Aprendizagem em ambientes virtuais: compartilhando ideias e construindo cenários. Caxias do Sul, RS: Educs, 2010. Disponível em < http://www.ucs.br/etc/revistas/index.php/aprendizagem-ambientesvirtuais/article/viewFile/393/323 >. Acesso em: 23 abr. 2013. p. 226-236.

SZYMANSKI, Heloísa. Entrevista reflexiva: um olhar psicológico sobre a entrevista em pesquisa. In: SZYMANSKI, Heloísa; ALMEIDA, Laurinda Ramalho de; BRANDINI, Regina Célia Almeida Rego. (Orgs.). A entrevista na pesquisa em educação: a prática reflexiva. Brasília: Líber, 2004, p. 9-61.

VIANNA, Heraldo Marelim. Pesquisa em educação: a observação. Brasília: Líber Livro Editora, 2007.

ZAVASKI, Ediana. Do real ao virtual: novas possibilidades das práticas pedagógicas nos laboratórios de informática. 2005. Dissertação (Mestrado em Educação) - Universidade Federal do Rio Grande do Sul, Porto Alegre.

Recebido em: 19/06/2013 Aprovado em: $26 / 09 / 2013$

Universidade do Estado de Santa Catarina - UDESC Programa de Pós-Graduação em Educação - PPGE 